\title{
Genes for Parasite-Specific, Nonhost Resistance in Populus
}

\author{
George Newcombe
}

Department of Forest Resources, University of Idaho, Moscow 83844.

Accepted for publication 2 March 2005.

\begin{abstract}
Newcombe, G. 2005. Genes for parasite-specific, nonhost resistance in Populus. Phytopathology 95:779-783.

Nonhost resistance is hypothesized to protect plants in a nonspecific manner. For highly specialized parasites, this hypothesis applies not only to distantly related plants but also to resistant congeners of the host species. Congeners of Populus spp. were hybridized to create two interspecific hybrid poplar pedigrees (i.e., Populus trichocarpa $\times$ P. deltoides and $P$. trichocarpa $\times P$. maximowiczii). The pedigrees were planted in a randomized, replicated "common garden" on Vancouver Island so that they were exposed to parasites of the native P. trichocarpa. Monogenic
\end{abstract}

ABSTRACT

In a series of articles and reviews (11-15), Heath has hypothesized that nonhost resistance is "basic" or parasite nonspecific. In contrast, major genes for resistance are known to be parasitespecific; they are thought to co-evolve with genes for virulence in gene-for-gene arms races within host and corresponding parasite populations (10). It is presumably only when a parasite overcomes basic, nonhost resistance that a coevolutionary arms race ensues. The initial, extreme susceptibility is thought to spark many generations of selection in both host and parasite. Repeated cycles of such selection ultimately result in parasite-specific, gene-for-gene interactions.

Differential, host-parasite specificity is the most basic indicator of gene-for-gene interactions in natural populations, even in the absence of evidence of pairs of corresponding resistance and avirulence genes. A summary of a study of four natural hostparasite associations (2) involving herbaceous plants has led to the view that spatial and temporal scale must be an explicit part of attempts to understand differential specificity. Theoretical models of natural, gene-for-gene coevolution often have been based on panmictic, single-population assumptions that do not reflect geographic scale and metapopulation dynamics (3). However, still unstudied among natural host-parasite associations are those that involve congeneric plants in which well-developed barriers of reproductive isolation are lacking. Incomplete barriers and occasional or local hybridization often characterize genera of longlived and woody plants (31), yet the implications for models of metapopulation gene-for-gene coevolution are unknown.

In Populus, there are many examples of parasite-specific, nonhost or "exapted" resistance $(23,24,26,27)$. Interspecific and even intersectional hybridization also are common in Populus spp. $(1,8)$, and its natural hybrid zones have become model laboratories in which susceptibility and resistance to parasites and other symbionts are studied (34). Hybrid populations may filter gene intro-

Corresponding author: G. Newcombe; E-mail address: georgen@uidaho.edu

DOI: 10.1094/PHYTO-95-0779

(C) 2005 The American Phytopathological Society and oligogenic resistance to two ascomycetous, parasitic fungi (i.e., Venturia inopina and a Taphrina sp.) segregated in a parasite-specific manner in each pedigree. However, these resistance genes were not inherited from the native host, $P$. trichocarpa. Instead, resistance was inherited from the allopatric, nonhost congeners, $P$. deltoides (eastern cottonwood) and $P$. maximowiczii (Japanese poplar). Thus, we found that major genes condition parasite-specific, nonhost resistance, as has been true in earlier studies of this kind with additional parasites of Populus spp. The selective force responsible for evolutionary maintenance of such genes is unknown.

Additional keywords: host range. gression between species (21), although subsequent selection for resistance to a parasite of a congener is impossible without exposure to that parasite.

Gene-for-gene interactions are known for Populus spp. in the case of Melampsora leaf rust (27). Populus trichocarpa and $P$. deltoides each are associated with a species of Melampsora (i.e., Melampsora occidentalis and M. medusae, respectively) and their wild distributions in western and eastern North America overlap slightly. $P$. trichocarpa possesses at least two major genes for rust resistance, Mmdl and Mxc3 (27,32). However, these cannot be detected by the native $M$. occidentalis in that the latter evidently lacks the avirulence alleles that correspond to these resistance genes. Instead, $M m d 1$ and $M x c 3$ are detected by avirulence genes in $M$. medusae and Melampsora $\times$ columbiana, respectively. $P$. deltoides itself possesses at least two major genes for resistance, $M x c 1$ and $M x c 2$, that are matched only by avirulence genes in some pathotypes of Melampsora $\times$ columbiana (27). The latter is the hybrid of M. medusae and M. occidentalis (28). Hybridization of both host and parasite congeners in the paired, continentally distributed systems have uniquely allowed differentially specific, gene-for-gene interactions to be detected. However, the evolutionary basis for these genes for resistance to Melampsora spp. is problematic. At least $M m d 1$ and $M x c 3$ specifically govern nonhost resistance to the parasite of a congener, $M$. medusae, and the basis for such selection is unknown.

$P$. trichocarpa is an undomesticated tree species that hosts fungal parasites other than Melampsora spp. Early studies have shown that the same pattern of major genes for parasite-specific, nonhost resistance prevails. For example, the resistance of hybrids of $P$. trichocarpa and $P$. deltoides to ascomycetous pathogens such as Glomerella cingulata (29) and Mycosphaerella populicola (24) was due to genes or quantitative trait loci (QTL), respectively, inherited from the nonhost, $P$. deltoides. In pursuit of generality, the genetic basis of resistance to additional, ascomycetous parasites was the focus of the present study. Interspecific hybridization was deliberately employed to create two three-generation pedigrees in which segregation for nonhost resistance could be analyzed. 


\section{MATERIALS AND METHODS}

The pedigrees. The $P$. trichocarpa $\times P$. deltoides pedigree comprises three generations: (i) 93-968 (P. trichocarpa O $) \times$ Ill129 ( $P$. deltoides $\precsim$ ); (ii) the $\mathrm{F}_{1}$ generation, of which 21 clones were in this field experiment, including the parents of the $\mathrm{F}_{2}, 53$ 246 and 53-242; and (iii) the $\mathrm{F}_{2}$, of which 103 clones were included in the field experiment. This $P$. trichocarpa $\times P$. deltoides pedigree also included reciprocal backcross progenies: (i) the $F_{1}$ female clone, 53-246, was crossed with Ill-129 to produce the backcross family $342(\mathrm{TD} \times \mathrm{D})$, of which 32 clones were included; and (ii) the $\mathrm{F}_{1}$ male clone, 53-239, was crossed with 93968 to produce the backcross family 353 (T×TD), of which 52 clones were included.

The $P$. trichocarpa $\times P$. maximowiczii pedigree also comprised three generations: (i) 8-1023 (P. trichocarpa + ) $\times$ MAX1016 $(P$. maximowiczii $\left.{ }^{\top}\right)$ and 8-1038 (P. trichocarpa + ) $\times$ MAX103 $(P$. maximowiczii $\left.{ }^{1}\right)$; (ii) the two $\mathrm{F}_{1}$ clones $(271-286$, a $\bigcirc$, and 27299, a $\lesssim$ ) that resulted from the above crosses and that were crossed to produce the $F_{2}$; and (iii) the $F_{2}$ family, of which 72 clones were included in the field experiment.

In addition, the following nonpedigree clones were included: 15 clones of each of $P$. trichocarpa, $P$. deltoides, and $P$. maximowiczii. The latter three sets included the abovementioned parental clones in addition to unrelated clones of each of the three species, and the species sets were used to check on the generality of resistance of nonhost congeners. In each of three, replicated blocks, each clone was represented by a two-ramet plot for a total of six ramets of each clone. Clones were randomized within each block.
The field experiment. As previously described (29), the site was an alluvial floodplain of the Salmon River $60 \mathrm{~km}$ north of Campbell River on Vancouver Island (latitude $50^{\circ} 12^{\prime} \mathrm{N}$, longitude of $125^{\circ} 48^{\prime}$, and elevation $<50 \mathrm{~m}$ ) where $P$. trichocarpa is the only native, wild representative of the two sections of Populus involved in this study: Tacamahaca and Aigeiros. Specifically, the field experiment was on Armishaw Road, south of the town of Sayward. Summers are moist and cool. Previous field experiments (29) established expectations for basic disease patterns for the new research, including the expectation that the parasites would take 4 or 5 years to become uniformly distributed throughout the new experiment on all susceptible individuals. Segregation for resistance to the three parasites thus was observed in the spring (Venturia and Taphrina spp.) and fall (Linospora spp.) of 2001 and 2002, although earlier data also were recorded. A fence kept out large mammalian herbivores, and cultivation controlled competition.

Parasites. Three fungal parasites were considered. Venturia inopina Newcombe only recently was distinguished from its European congener, V. populina (Vuill.) Fabric. (25). The former parasitizes $P$. trichocarpa whereas the latter occurs in the Pacific Northwest on its European host, P. nigra cv. italica. Young leaves and shoots of $P$. trichocarpa are blighted in the spring by $V$. inopina, resulting in necrotic lesions.

The second, ascomycetous parasite is a native species of Taphrina, adapted to $P$. trichocarpa and its hybrids. Critical studies of $T$. populina (Fr.:Fr.) Fr. and T. populi-salicis mix are unavailable; therefore, the Taphrina sp. of this study is simply referred to as a Taphrina sp. that causes a leaf blister in spring.

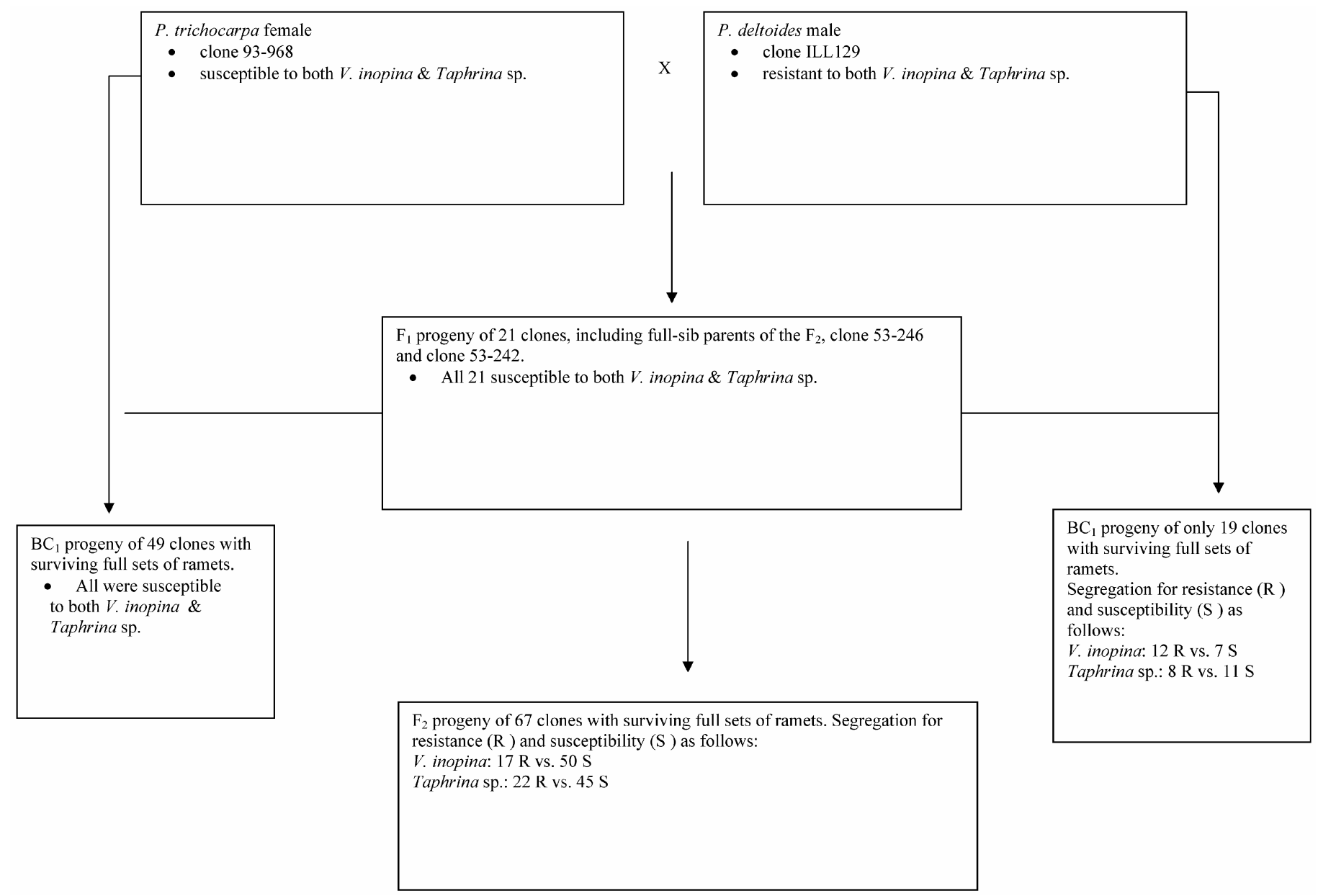

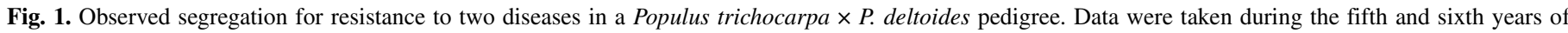

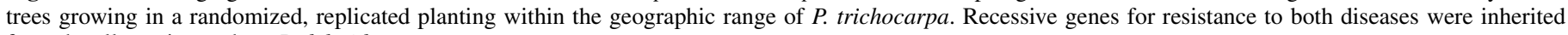
from the allopatric, nonhost $P$. deltoides. 
Typically, yellow asci of Taphrina spp. develop on the concave surface of the blister.

Linospora tetraspora G. E. Thompson is also a foliar parasite of $P$. trichocarpa that develops later in the season than $V$. inopina or the Taphrina sp. Black fruiting bodies of the fungus speckle the light-brown lesions. Symptoms of the three parasites are easily distinguished, and microscopic confirmation of symptom-based diagnosis also is simple.

Assessment of resistance. Individuals (clones) were assessed as either resistant or susceptible in the fifth and sixth years of growth. During the fifth year, clones were recorded as resistant if, during any year up to that point, none of their ramets had been judged susceptible to a particular parasite. The sixth year was used to confirm the segregation patterns of the fifth year. Any diagnosable symptoms on any ramet of a particular clone at any time in the fifth or sixth years resulted in a classification of "susceptible".

\section{RESULTS}

Resistance to $\boldsymbol{V}$. inopina in the $P$. trichocarpa $\times P$. deltoides pedigree. All 15 clones of the native host, $P$. trichocarpa, were susceptible to $V$. inopina, whereas the 10 surviving clones of the original 15 of the nonhost congener, $P$. deltoides, were resistant in both the fifth and sixth years. Resistance to $V$. inopina in the $P$. trichocarpa $\times P$. deltoides pedigree did not segregate in the $\mathrm{F}_{1}$, because all 21 clones were susceptible (Fig. 1). Of the original $F_{2}$ progeny of 103 clones, 67 survived with full sets of ramets into the fifth and sixth years. Even though the $F_{1}$ parents of the $F_{2}$ were both susceptible, there was segregation in the $F_{2}$ that suggested a single, recessive gene for resistance (50 clones were susceptible and 17 were resistant). The latter observed ratio does not deviate significantly from the $3: 1$ ratio $\left(\chi^{2}=0.005 ; P=0.94\right)$ expected for a recessive gene. Of the 50 susceptible clones, 28 displayed $100 \%$ incidence, in that all ramets were symptomatic in both the fifth and sixth years of growth. Incidence and disease severity varied among ramets and years for the other 22 susceptible clones. Of the 36 clones that did not survive in full into the fifth and sixth years, all data suggested segregation in line with the $3: 1$ ratio of the 67 survivors. In the T $\times$ TD backcross progeny, 49 of 52 clones survived in full and all were susceptible, as would be expected for a cross between the dominant homozygote for susceptibility (P. trichocarpa female 93-968) and a susceptible $F_{1}$ heterozygote (53-239). In contrast, survival in the TD $\times \mathrm{D}$ backcross progeny was poor (19 of the original 32 ). Other than noting that there was segregation, in that 7 clones were susceptible and 12 resistant, the expected 1:1 ratio (susceptible $F_{1}$ heterozygote [53-246] $\times$ resistant homozygote $[P$. deltoides male ILL-129]) was not tested.

Resistance to $V$. inopina in the $P$. trichocarpa $\times P$. maximowiczii pedigree. As already stated, all 15 clones of the native host, $P$. trichocarpa, were susceptible to $V$. inopina. In this case, all 15 clones of the nonhost congener, $P$. maximowiczii, survived and all were resistant in both the fifth and sixth years. Both $F_{1}$ clones, parents of the $\mathrm{F}_{2}$, were resistant (Fig. 2). These results were expected, given the previous study (23) in which $32 / 32$ and $36 / 36$ clones of $P$. maximowiczii and $P$. trichocarpa $\times P$. maximowiczii $\mathrm{F}_{1}$ hybrids, respectively, were resistant to $V$. inopina. In this study, of the original $F_{2}$ progeny of 72 clones, 64 survived with full sets of ramets into the fifth and sixth years. Of these, 61 were resistant but 3 were susceptible. Observed segregation in the $\mathrm{F}_{2}$ thus fits a dihybrid ratio of $15: 1\left(\chi^{2}=0.267 ; P=0.605\right)$. In other words, when a $P$. trichocarpa $\times P$. maximowiczii $\mathrm{F}_{2}$ individual possesses a dominant allele at either of two, independent loci, it is resistant. Only individuals that are homozygous recessive at both loci appear to be susceptible.

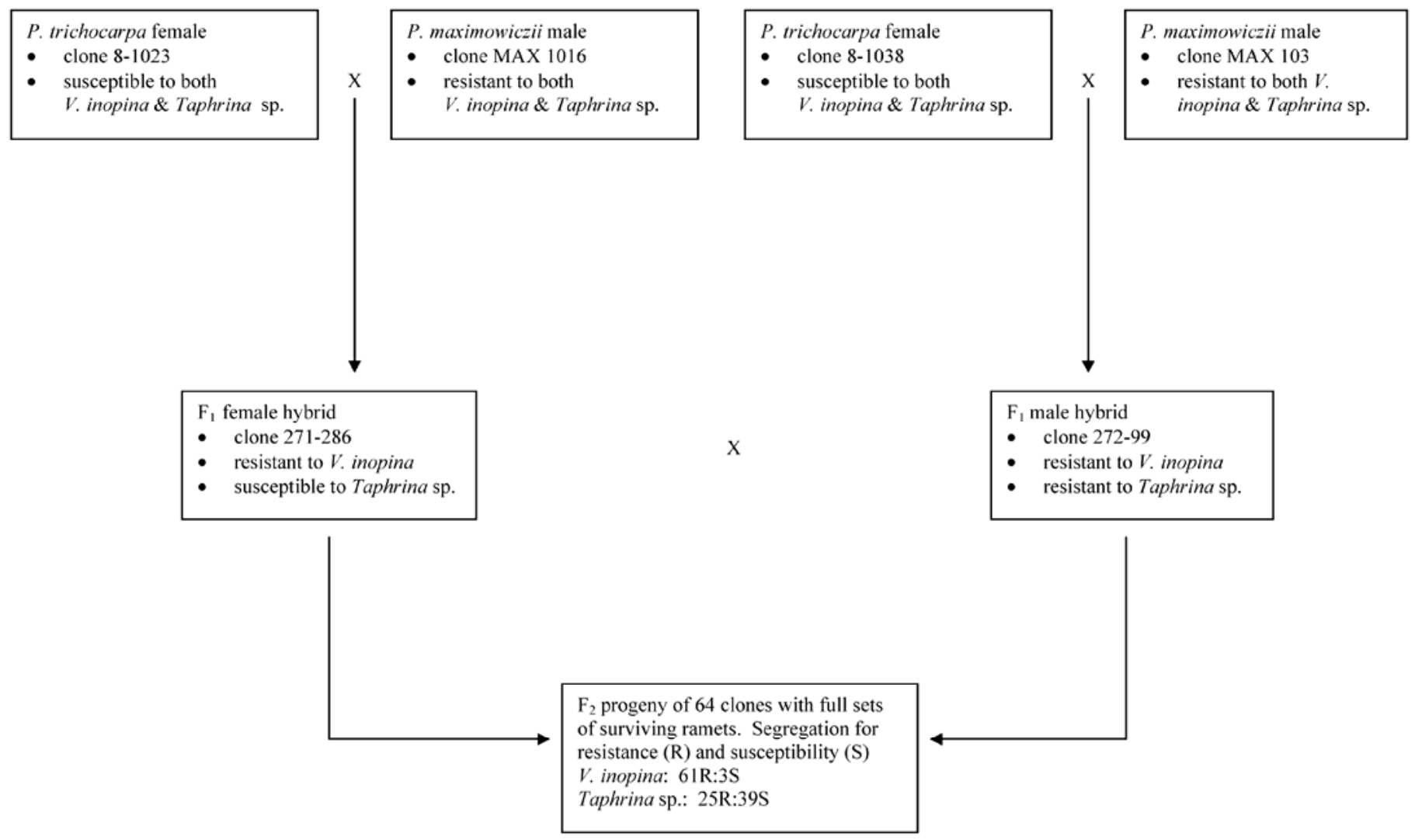

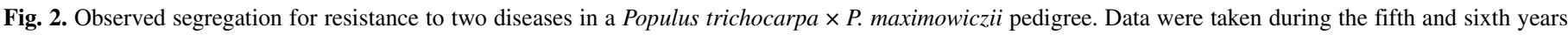

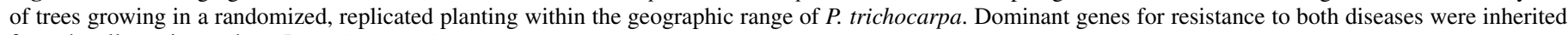
from the allopatric, nonhost $P$. maximowiczii. 
Resistance to a Taphrina sp. in the $P$. trichocarpa $\times P$. deltoides pedigree. Again, the entire set of clones of $P$. trichocarpa was susceptible, whereas the nonhost, congeneric clones of $P$. deltoides were resistant. All $21 \mathrm{~F}_{1}$ clones were susceptible, but the $\mathrm{F}_{2}$ segregated (i.e., 45 susceptible and 22 resistant individuals) (Fig. 1). As with resistance to $V$. inopina in the $P$. trichocarpa $\times$ $P$. deltoides pedigree, the latter observed ratio corresponds to the $3: 1$ ratio $\left(\chi^{2}=2.2 ; P=0.14\right)$ expected of a recessive gene for resistance. Similarly, the 49 clones of the $\mathrm{T} \times \mathrm{TD}$ backcross progeny were susceptible, as would be expected for a cross between the dominant homozygote for susceptibility (P. trichocarpa female 93-968) and a susceptible $F_{1}$ heterozygote (53-239). Both susceptible and resistant clones were observed in the TD $\times D$ backcross progeny as expected; however, again, survival was poor as noted above.

Resistance to a Taphrina sp. in the P. trichocarpa $\times P$. maximowiczii pedigree. The resistance of the nonhost congener, $P$. maximowiczii, again contrasted qualitatively with the susceptibility of $P$. trichocarpa. One of the $F_{1}$ parents was susceptible (the female clone 271-286), whereas the other was resistant (the male clone 272-99). Of the 64 surviving $F_{2}$ clones, 39 were susceptible and 25 resistant. This observed ratio was tested against the 1:1 ratio expected for a dominant gene in a cross between a susceptible recessive homozygote and a resistant heterozygote $\left(\chi^{2}=3.06 ; P=0.08\right)$. In this case, a dominant gene inherited from a heterozygous $P$. maximowiczii is the simplest explanation for resistance.

Resistance to $L$. tetraspora in both the $P$. trichocarpa $\times$ $\boldsymbol{P}$. deltoides and $\boldsymbol{P}$. trichocarpa $\times \boldsymbol{P}$. maximowiczii pedigrees. No segregation was observed in the two pedigrees because all clones were at least somewhat susceptible, varying in quantitative extent. However, the expected resistance of the two nonhost congeners was confirmed.

Linkage of the two recessive genes for resistance to $V$. inopina and a Taphrina sp. in the $P$. trichocarpa $\times P$. deltoides pedigree. Contingency testing for linkage of these two recessive genes indicated that they are linked $\left(\chi^{2}=4.1 ; P=0.04\right)$.

\section{DISCUSSION}

Resistance to parasites of allopatric congeners is not inherently surprising. Although examples such as chestnut blight suggest generalized susceptibility to parasites of congeners, resistance is implied in "enemy release" (16), whereby exotic plants are not only unaffected by parasites left behind in the continent of origin, but also are resistant to parasites of congeners of their host in the new land. Recent studies have suggested that exotic plants become invasive in part because they are resistant to root pathogens that limit the growth of related, native plants $(4,17)$. Nonhost, gene-for-gene interactions have even been demonstrated between a New World plant (i.e., maize) that possesses an $R$ gene that matches an avirulence gene in an Old World pathogen (i.e., a bacterial pathogen of rice) (36). Finally, resistance to parasites of congeners would appear simply to be a given because specialized parasites possess narrow host ranges.

But why are host ranges narrow? Findings here imply that the reported genes (Table 1) limit the host ranges of $V$. inopina and

TABLE 1. Inheritance of parasite-specific, nonhost resistance to parasites of Populus trichocarpa on Vancouver Island ${ }^{\mathrm{a}}$

\begin{tabular}{lcc}
\hline & \multicolumn{2}{c}{ Nonhost resistance inherited from } \\
\cline { 2 - 3 } Parasite & \multicolumn{1}{c}{ P. deltoides } & P. maximowiczii \\
\hline $\begin{array}{l}\text { Venturia inopina } \\
\text { Taphrina } \text { sp. }\end{array}$ & \multicolumn{1}{c}{ Single recessive gene } & Two dominant genes \\
\hline a Contingency testing for linkage of the two recessive genes inherited from \\
$P$. deltoides: $\chi^{2}=4.1(P=0.04)$.
\end{tabular}

the Taphrina sp. that parasitize $P$. trichocarpa. It could be argued that resistance in Populus is anomalous and that only broader investigations of more plant taxa with confirmation of the Populus pattern will allow for generalization. However, the use of resistance genes of wild relatives in crop breeding (20) suggest that the genus Populus is not anomalous. Of course, only congeneric plants that can be hybridized would be candidates for broader investigations of major genes for nonhost resistance.

Could the existence of parasite-specific, major genes for nonhost resistance depend on selective filtering through natural hybrid zones (21)? Filtering of this sort has been possible for millions of years (7) where the ranges of $P$. deltoides and $P$. trichocarpa overlap and these North American congeners hybridize. However, hybrid-zone filtering could not account for the parasitespecific, nonhost resistance displayed in this study by the Asian poplar, $P$. maximowiczii. This hypothesis would not, in any case, account for post-zone maintenance of genes for resistance in the absence of selection exerted by the corresponding parasite.

$P$. deltoides and $P$. maximowiczii are susceptible to diseases caused by Venturia and Taphrina spp. within their own native ranges. $P$. deltoides is known to be susceptible to its own hostadapted populations of Taphrina (19) and Venturia $(9,22)$; the same is likely to be true for $P$. maximowiczii $(22,35)$. Earlier studies of resistance to G. cingulata (24) and M. populicola (26), in which genes or QTL were inherited from the nonhost (i.e., $P$. deltoides), also potentially could be explained in terms of selection due to sympatric, host-adapted populations. However, evidence to date does not favor this hypothesis. For example, there was no phenotypic evidence for a major gene for resistance to Melampsora occidentalis in P. trichocarpa populations in common gardens (6), nor was there in an inoculation study (28). If the $M m d l$ and $M x c 3$ genes were retained in P. trichocarpa through selection for resistance to $M$. occidentalis, then at least some resistant clones would have been detected in these studies. Similarly, in the study reported here, the 15 clones of $P$. trichocarpa all were susceptible to three ascomycetous parasites (i.e., $V$. inopina, a Taphrina sp., and L. tetraspora) in a common garden within its native range. Predictions supported by this study and its earlier counterparts include: (i) outside its native range, $P$. trichocarpa would be resistant to populations of Venturia, Taphrina, and Linospora spp. to which the local species of Populus would be susceptible; and (ii) interspecific hybrids of the local species and $P$. trichocarpa would express resistance conferred by genes inherited from $P$. trichocarpa (even though this study provided no evidence that $P$. trichcarpa possesses genes for resistance to its own parasite populations).

Major genes for parasite-specific or pathotype-specific resistance in crop plants usually are assumed to have resulted solely from coevolutionary arms races $(5,18,30,33)$, rather than from domestication-associated hybridization in which genes for resistance were inadvertently or deliberately obtained from wild relatives. The arms-race paradigm provides a compelling example of natural selection and, thus, an easily accepted explanation for major genes for resistance. In contrast, the genes reported here and in earlier studies of resistance to parasites of Populus spp. cannot be explained by simple, coevolutionary arms races. In particular, the selective force responsible for the evolutionary maintenance of such genes is not yet known.

\section{ACKNOWLEDGMENTS}

The research was supported by the former Biofuels Feedstock Development Program (U.S. Department of Energy) that was led by J. Tuskan. We thank R. Stettler and T. Bradshaw for developing the pedigrees; J. Staley, G. Ekuan, and J. Whisler for helping to establish the field experiment; J. Dunlap for helping to record observations in 1998 and 1999; and C. van Oosten and B. Rogers for ensuring plot maintenance and year-to-year continuity. 


\section{LITERATURE CITED}

1. Barnes, B. V. 1967. Indications of possible mid-Cenozoic hybridization in the aspens of the Columbia Plateau. Rhodora 69:71-81.

2. Burdon, J. J., and Thrall, P. H. 1999. Spatial and temporal patterns in coevolving plant and pathogen associations. Am. Nat. 153:S15-S33.

3. Burdon, J. J., Thrall, P. H., and Lawrence, G. J. 2002. Coevolutionary patterns in the Linum marginale-Melampsora lini association at a continental scale. Can. J. Bot. 80:288-296.

4. Callaway, R. M., Thelen, G. C., Rodriguez, A., and Holben, W. E. 2004. Soil biota and exotic plant invasion. Nature 427:731-733.

5. Crute, I. R. 1998. The elucidation and exploitation of gene-for-gene recognition. Plant Pathol. 47:107-113.

6. Dunlap, J. M. 1991. Genetic variation in natural populations of Populus trichocarpa T. \& G. from four river valleys in Washington. Ph.D. thesis, University of Washington, College of Forest Resources, Seattle.

7. Eckenwalder, J. E. 1984. Natural intersectional hybridization between North American species of Populus (Salicaceae) in sections Aigeiros and Tacamahaca. Paleobotany and evolution. Can. J. Bot. 62:336-342.

8. Eckenwalder, J. E. 1984. Natural intersectional hybridization between North American species of Populus (Salicaceae) in sections Aigeiros and Tacamahaca. II. Taxonomy. Can. J. Bot. 62:325-335.

9. Farr, D. F., Rossman, A. Y., Palm, M. E., and McCray, E. B. 2004. Fungal Databases. Systematic Botany and Mycology Laboratory, United States Department of Agriculture-Agricultural Research Service.

10. Flor, H. H. 1991. Current status of the gene-for-gene concept. Annu. Rev. Phytopathol. 9:275-296.

11. Heath, M. C. 1987. Evolution of parasitism in the fungi. In: Evolutionary Biology of the Fungi. A. D. M. Rayner, C. Brasier, and D. Moore, eds. Cambridge University Press, Cambridge.

12. Heath, M. C. 1991. The role of gene-for-gene interactions in the determination of host species specificity. Phytopathology 81:127-130.

13. Heath, M. C. 1991. Tansley review no. 33. Evolution of resistance to fungal parasitism in natural ecosystems. New Phytol. 119:331-343.

14. Heath, M. C. 1995. Thoughts on the role and evolution of induced resistance in natural ecosystems, and its relationship to other types of plant defenses against disease. In: Induced Resistance to Disease in Plants. R. Hammerschmidt and J. Kuc, eds. Kluwer Academic Publishers, Dordrecht, The Netherlands.

15. Heath, M. C. 2002. Cellular interactions between biotrophic fungal pathogens and host or nonhost plants. Can. J. Bot. 24:259-264.

16. Keane, R. M., and Crawley, M. J. 2002. Exotic plant invasions and the enemy release hypothesis. Trends Ecol. Evol. 17:164-170.

17. Klironomos, J. N. 2002. Feedback with soil biota contributes to plant rarity and invasiveness in communities. Nature 417:67-70.

18. Ladle, R. J. 1992. Parasites and sex: Catching the red queen. Tree 7:405408.
19. Leininger, T. D., Redlin, S. C., and Nebeker, T. E. 1995. Yellow leaf blister caused by Taphrina populina on eastern cottonwood in Mississippi. Plant Dis. 79:967.

20. Lenne, J. M., and Wood, D. 1991. Plant diseases and the use of wild germplasm. Annu. Rev. Phytopathol. 29:35-63.

21. Martinsen, G. D., Whitham, T. G., Turek, R., and Keim, P. 2001. Hybrid populations selectively filter gene introgression between species. Evolution 55:1325-1335.

22. Mix, A. J. 1949. A monograph of the genus Taphrina. Univ. Kans. Sci. Bull. 33:3-167.

23. Newcombe, G. 1998. A review of exapted resistance to diseases of Populus. Eur. J. For. Pathol. 28:209-216.

24. Newcombe, G. 2000. Inheritance of resistance to Glomerella cingulata in Populus. Can. J. For. Res. 30:639-644.

25. Newcombe, G. 2003. Native Venturia inopina sp. nov., specific to Populus trichocarpa and its hybrids. Mycol. Res. 107:108-116.

26. Newcombe, G., and Bradshaw, H. D., Jr. 1996. Quantitative trait loci conferring resistance in hybrid poplar to Septoria populicola, the cause of leaf spot. Can. J. For. Res. 26:1943-1950.

27. Newcombe, G., Stirling, B., and Bradshaw, H. D., Jr. 2001. Abundant pathogenic variation in the new hybrid rust Melampsora $\times$ columbiana on hybrid poplar. Phytopathology 91:981-985.

28. Newcombe, G., Stirling, B., McDonald, S., and Bradshaw, H. D., Jr. 2000. Melampsora $\times$ columbiana, a natural hybrid of $M$. medusae and $M$. occidentalis. Mycol. Res. 104:261-274.

29. Newcombe, G., and van Oosten, C. 1997. Variation in resistance to Venturia populina, the cause of poplar leaf and shoot blight in the Pacific Northwest. Can. J. For. Res. 27:883-889.

30. Staskawicz, B. J., Ausubel, F. M., Baker, B. J., Ellis, J. G., and Jones, J. D. G. 1995. Molecular genetics of plant disease resistance. Science 268:661-667.

31. Stebbins, G. L. 1993. Concepts of species and genera. Pages 229-246 in: Flora of North America. F. O. N. A. E. committee, eds. Oxford University Press, New York.

32. Stirling, B., Newcombe, G., Vrebalov, J., Bosdet, I., and Bradshaw, H. D., Jr. 2001. Suppressed recombination around the Mxc3 locus, a major gene for resistance to poplar leaf rust. Theor. Appl. Genet. 103:1129-1137.

33. Thompson, J. N., and Burdon, J. J. 1992. Gene-for-gene coevolution between plants and parasites. Nature 360:121-125.

34. Whitham, T. G. 1989. Plant hybrid zones as sinks for pests. Science 244:1490-1493.

35. Wu, W. P., and Sutton, B. C. 1995. Further observations on Pollaccia mandshurica, a pathogen of Populus spp. in China. Mycol. Res. 99:983-986.

36. Zhao, B., Ardales, E. Y., Raymundo, A., Bai, J., Trick, H. N., Leach, J. E., and Hulbert, S. H. 2004. The avrRxol gene from the rice pathogen Xanthomonas oryzae pv. oryzicola confers a nonhost defense reaction on maize with resistance gene Rxo1. Mol. Plant-Microbe Interact. 17:771-779. 